\title{
Discussion on Service Marketing for Gallery Management in Free Opening Age
}

\author{
Wei Tu \\ School of Art and Design \\ Wuhan University of Science and Technology \\ Wuhan, Hubei, China 430065
}

\author{
Cuicui Liu \\ School of Art and Design \\ Wuhan University of Science and Technology \\ Wuhan, Hubei, China 430065
}

\begin{abstract}
With the rapid development of gallery business in our country, it provides convenient diversified cultural service. In free opening age, the gallery managers and servers shall connect the gallery operation and market operation, and on the base of virtuous circle with public relations, expand service and management concepts in accordance with audiences' requirements from the view of marketing to play the due social function of gallery. In this article, it takes services marketing view as the starting point and injects flesh blood into the development of gallery, the national non-profit cultural organization from the building and management of gallery staff to audience factors of the staff management of gallery, so as to better play its public education function, serve the society and promote faster and better development of national public cultural undertakings.
\end{abstract}

Keywords—gallery management; service marketing; non-profit organization; marketing

\section{INTRODUCTION}

\section{A. Development of Gallery in China}

According to statistics, as of the end of 2011, there had been 15 provinces where their galleries are opening to public for free, however, in comparison with 2,400 museums, 3,285 cultural centers, 34,139 township integrated cultural stations having been free opening to public, it is comparatively lagging behind. In November 2012, the eighteenth national congress of the communist party of China further indicated that it will continuously promote public cultural service facilities free opening to society and enhance the whole national cultural creative vitality. It shows in the Statistical Bulletin of Cultural Development in 2015 of Ministry of Culture of the People's Republic of China that, as of the end of 2015, there are 299.1 thousand of cultural units belonging to national cultural system, increasing by 11.8 thousand units than last year; 2.2944 million employees, increasing by 254.2 people, of which, 65714 units belonging to cultural heritage departments at all levels, increasing by 152 and 925.08 million person times of audience reception in the whole year, increasing by $9.8 \%$ year to year. The rapid development brings challenges to the venues parties, audiences and the whole society, so that it becomes an issue which needs to deeply study and discuss for long time in the future concerning better and effectively playing the functions of gallery.

\section{B. Burning Questions with the Rapid Development after Free Opening of Gallery}

In the 3 processes the gallery experienced, it has passed the conversion of "collection-oriented" to "People-oriented", which is even more obvious in recent years, correspondingly the work center of gallery gradually turns to the analysis and discussion on gallery audiences as well as the research on the public educational propaganda capacity of the gallery. Whether the gallery can retain audiences and its art educational knowledge propaganda can promote audiences in spirit, is a key condition to evaluate this non-government institution. However, the above said is only one of aspects retaining audiences, and only combining with the market demands and marketing, can it better realize the effect of public education on audiences.

Therefore, how to attract masses to enter the gallery, popularize current art and fully utilize gallery to play the function of public educational knowledge propaganda; how to manage gallery and retain audiences who long for gallery knowledge education as much as possible; how to keep up with the flourishing cultural development in China and form practically effective gallery management mode to benefit the whole people from gallery education, have become the burning issues of the times in the sound development of gallery business.

\section{CONCEPTION OF SER VICE MARKETING}

Service marketing, as an importation component of marketing, is an economic phenomenon occurring upon the consumption level of current service economic times reaching certain level, an effective approach for enterprises achieve advantages in the intensive market competition currently and a qualitative leap of marketing theory of enterprise. Because of rapid development of scientific technology and progress of social production as well as day-by-day speeding up of the upgrade industries and professional development of production, on the one hand, the service content (service density of product) of product increases day by day, and on the other hand, with the promotion of labor production rate, the income level of customers promotes continuously, the market gradually turns to buyer from seller, the market consumption demands also change gradually to market diversification direction. Under thus social demand, service marketing plays more and more 
important function and has a more important status in enterprise marketing management, and it requires that service industry must have a deep understanding on customer demands and take series of activities in marketing process of meeting the service demands of customers. In other words, if gallery and other non-profit cultural organization want to make audiences visit the gallery for multiple times and enjoy the cultural education air it brings when fully meeting the visual psychology requirements of the audiences, then it shall take corresponding activities as well.

Service, as an intangible product, is hard for audiences to judge its quality and effect, while the reality of service can be embodied and formed through audiences' five sense organs. However, most time, it is allowed to evaluate service through some realistic sites and facilities provided for services, such as comfortable and close service site and servers with high professional quality and strong moral idea, but to let audiences have concrete judgment on intangible products, it requires to pay enough attention on the tangible parts of services, make intangible services to be tangible, mobilize audience emotion through favorable services and build unique service environment.

\section{OPERATION OF SER VICE MARKETING MANAGEMENT} Strategy IN GALlery MANAGEMENT In FreE OPENING AgE

\section{A. Building and Management of Gallery Staff}

Firstly, in this information-integrated age, the management strategy of "people-oriented" of service marketing determines that staff is the priority among priorities of service marketing mix. The management factors of gallery staff compose of two categories, one is staff of gallery per se (including artists, management teams of gallery, managers and servers), and in the development process of gallery, although capital matters of existence, it is not the only factor, while the fundamental reasons for existence are the excellent innovative ability of gallery team as well as advanced idea of gallery operation. Gallery devotes itself all the time to actively participating in and promoting the program and development of the cultural artistic business of China, and operates with advanced ideas, scientific management methods as well as sustainable development strategy and hope that a road to survival more suitable for the galleries of our country can be found. Only the gallery establishes high-level venue by adopting up-andcoming ideas, introduces professional management and operation talents of gallery, strengthens internal management and team construction and promotes the qualities of gallery servers, can provide important security for the development of gallery.

And that, audiences pay more and more attentions on satisfaction they acquiring in the consumption process of commodities and services, and service marketing exactly is a marketing concept provided arising from the current market development, unlike traditional marketing concept, the core idea of service marketing is to improve the customer satisfaction and loyalty to promote mutually favorable exchange, so as to drive the development of industry. In addition to product per se, services have become the main mean to acquire advantages in market competition, the foundation of service marketing is customer satisfaction, as well as the direct objective and final destination for enterprise manufacturing and providing services, and as a concrete marketing mean, service marketing is throughout the whole process of the entire marketing. In recent years, more and more visitors enter galleries for edification and education of beauty, which brings more pressure to gallery already short of hands. According to Xinhua net report, as of the end of 2012, there had been 265 galleries and 2782 employees in total belonging to national cultural system, of which, there were 1497 professionals, less than 6 per gallery evenly. Moreover, most of gallery servers are volunteers with high mobility, which is very adverse for talent training. Hence, each gallery introduces and strives for talents with might and main, after all, retaining talents is the fairly important condition for the long-term development of gallery.

Under the halo of works and artists, gallery practitioners are considered as mystical, cold and elegant group. Nevertheless, along with the increase of institution quantity year by year, incoming of international project, day-by-day subdivision of Catholic activities, the recruitment by law of gallery emerges little by little. "Previously, internal recommendation adopted to make up the gallery's demand for talent in most cases, and now we recruit on line all the year around." said by Wang Weiwei, curator of Museum of Contemporary Art Shanghai. Opening the homepage of several galleries and clicking "join us" plate can clearly know the recruitment situation.

Such as, Long Museum opens about 30 posts to public, including 3 for university press, 3 for collection and exhibit, 3 for business development, 1 for graphic design, 2 for financing and 2 for administration; Rockbund Art Museum is recruiting a administrative specialist, and the educational specialist post which has been open on line for over one month was "off the line" few days ago; the Museum of Contemporary Art Shanghai indicates that, the educational specialist, curatorial assistant, admin specialist and designer are reserved. Besides regular employees, almost all the galleries have the plan of recruiting interns over 3 months. Currently, the gallery provides intern posts, covering main departments of gallery and according to the majors of the interns, they will be arranged at exhibition center, development center, academic center and the research institute of contemporary art, and with the abundant posts, it makes completely preparation of talent reservation. The recruitment advertising is more and more transparent, which seems to bring more chances for job seekers. However, multiple practitioners of gallery indicate that "It's difficult to recruit proper personnel".

Secondly, the service per se of services marketing is its own product, however, the personnel of service industry is more the main body of service than an important production factor. In the whole process of transmitting services, personnel is the relational tie linking services industry and audiences, playing an indispensable function. With the individuality of market consumption demands and personality of service day by day, the server gets closer with audiences, and in the whole process of services provided by the personnel, the performance of who become the important standard to evaluate the quality situation of service industry. Therefore, service industry pays 
more attention on the selection, training and management of personnel in comparison with other industries. The core of people-oriented management is people-oriented, fully understands, respects and motivates people's enthusiasm, meets people's rational demand and affirms people's subject function in production operation activities of the enterprise, so as to further motivate people's enthusiasm and creativity. The practitioner of gallery is its internal audience as well, by adopting the management strategy of "people-oriented", it builds harmonious work atmosphere, better promotes the loyalty of practitioners to gallery, fully plays their abilities and realizes their value, so that it will transmit the gallery's public education better and more accurately and form personnel's sense of belonging to enterprises in the process of actively working and management and make them working in the enjoyable, relaxed, harmonious and amicable atmosphere. Only completely motivating the most active factor in production capacity, can improve the service quality fundamentally, make the service marketing concept become the personnel's common value and code of conduct as well as make the organization and personnel can be optimized.

Previously, most research scholars think that, things at the realistic level are the main resistance resisting masses getting close to art, while some investigations show out the importance of psychological obstacle. In recent years, the cultural institutions adopt lots of methods to eliminate these obstacles, and the more important thing is that the personnel of the museums and galleries shall provide amiable and considerate services, contact audience with amity, enthusiasm and high cultural sensitivity instead of making any people who participates in cultural activities feel strange or distant. Hence, gallery shall conduct observation and statistics on the audiences' visiting behaviors, so that it can provide more abundant and qualified services according to the customers' respective demand to weaken the psychological obstacles of different target groups, meet their different concrete requirements, so as to lead them to enter galleries to perfect self-development and realize their spiritual pursuit.

In addition, as a non-profit organization, gallery needs system as security and reformation and innovation injecting flesh blood more need talent team construction to bring prosperity and development. At present, the practical condition of rapid development and diversified function positioning of gallery require that, the gallery must envisage the practice of lacking of professional talents, seize the opportunity of the age, create advantage conditions, attract more excellent talents by hook or by crook, well carry out the strategy of strengthening the gallery on talent as well as conduct talent training, talent selection and talent utilization. The gallery requires staff with wide professional background, abundant professional fields and different professional degrees, therefore, gallery shall pay more attention on discovery of talents, strengthen training of professional talents and expand cooperation channels of socialized talents. Continuously promote gallery practitioners' business quality and professional work ability by means of induction training, work practice, inspection study and strengthening the proficiency of counterpart communication and training business, and only effectively respecting professional technologies, fully supporting individuality development and deeply digging personal capacity, can manage to management in place and cultivate a big group of excellent talents meeting the requirements of gallery function. Similarly, in the process of construction, the gallery team shall emphasize flow cooperation and coordination spirit, and play the intelligence of every single person to form a whole powerful strength through mutual cooperation. On the basis of fixed posts for certain person and devotion, it requires that every staff must make clear the work flow, fulfill their post responsibilities responsibly in order according to the rules and regulations.

\section{B. Audience Factors of Gallery Personnel Management}

The secondary factor of gallery personnel management is audience, as the "customer" of the gallery, audience is the reason why gallery exists, while "service marketing" is a marketing mean further providing related services through focusing on "consumption group" and finally realizing advantageous exchange. Hence, for gallery implementing services marketing, it must make clear the service objective firstly, e.g. "who is the audience". It means that, gallery shall sort the "target audience group" served and to be served and analyze the visit motivation, including gender, age, area, level of education and interest to gallery activities. It can be current audience and potential audience. Secondly, the gallery must subdivide the audience groups according to its own purpose, meanwhile lock and understand its objective audience group. It is understood that gallery activities are mainly for children art, the effect of which is also relatively obvious, successively are semi-/quasi-professional audiences (there are over 1400 colleges and universities setting up related art and design majors all over the country and 1.4 million undergraduates) and other social masses. According to the above, the gallery shall implement more art activities meeting the demand of most audience groups. Taking Hubei gallery as an example, it often holds some art education activities with high public interactivity, such as Tingtao Lecture, book club, children art exhibition as well as related collection of creative works. And other investigations show that, the audiences' satisfaction degree (including convenience degree for visit) on hardware far higher than software environment; the degree of satisfaction on the gallery carrying out activities rises year by year, and the investigation shows that nearly one third of visited audiences indicate their will to visit again, and audiences who may visit again and have no idea exceed $60 \%$, and all the above-mentioned feedbacks of audiences indicate that there is still huge space urgent to promote of the gallery's educational advertising effect.

The market in the face of services marketing is constantly changing conditions, and only audiences feel easy and enjoyable in the gallery and have sense of identity to art, can they repeatedly visit the gallery. Therefore, galleries shall devote themselves to thus a objective that, explain the component factors of being easy, enjoyable and satisfied when visiting gallery in details, and sketch a clear venation that how the audiences discover these factors within shortest and most effective time in gallery space, so as to make them spend minimum time and energy for more values in gallery. 
In the process of managing gallery services marketing, by means of explanation, even reappearance and promotion, the professional servers effectively bring the information chain to the audiences and potential audiences along with other departments. Make people who hardly visit or have no possibility to visit gallery due to social reasons participate in the activities, convert the potential audiences to true audiences, so as to drive the healthy and sustainable development of gallery and national cultural industry. In addition, the gallery shall be made to not only take the exhibition, collection, research, public education and services as main functions, but also become the entertainment centre, so as to be really integrated into masses' lives.

\section{CONCLUSION}

"In 21st century, gallery is not divided into public and private ownership in the true sense, and the operation mode of all the institutions will transform into an enterprise." said by Philip Dodd, the founder of Global Private Museum Summit in November 2015, and the words may be the important trend of galleries in the future. We shall organize to produce and promote proper "products" of gallery according to the gallery's own characteristics through ideas and methods of enterprise operation, so as to meet the demands of customers and society, and accomplish the final objective of serving society, although this definition is with business market mark, the consciousness that "accomplishing the final objective of serving society" shows that it has made a big progress comparing to previous pure business view. Generally, the marketing theory of gallery at present stage is still in exploration stage of "crossing the river by feeling the stones", which still needs the continuous examination of practice. We should have such consensus that, gallery should be an institution of "services" "opening to public" in the first place, and only it has enough serviceability, can it "be applauded and draw a large audience".

\section{REFERENCES}

[1] An Laishun. Assessment Report to the Operation of National First-grade Museum in 2010 [J]. Chinese Museum. 2012 supplement.

[2] Huang Yaqun. Reflection on the Public Education of Current Gallery Art - by Comparison with the Art and Public Education Relationship between China and the West [J]. New West. 2010 (4).

[3] Chen Xiangbo. Guan Shanyue Art Museum Highlighting the Culture Positioning of Shenzhen - Reflection on the Operation Mode of Nonprofit Gallery [J]. Art. 2011 (11).

[4] Yu Ding, Lv Xiaoxiao. Restricted View on the Public Art Education of Gallery - Starting from American Gallery Education [J]. Studio of Glorious Treasures. 2011 (4).

[5] Gao Min. From Collections to Audiences - Conversion of Gallery Center of Attention [J]. Art Journal. 2010 (5).

[6] Kui Lianhui. the Pageant of Asian Galleries - Summary of the Fifth Asian Art Museum Directors' Forum [J]. Hundred Schools in Arts. 2011 (11).

[7] Li Yukukn. Contemporary Art and Education of Gallery [J]. Hundred Schools in Arts. 2005 (1).

[8] Dong Ping. Free Opening and Construction of Public Service System of Gallery Culture [J]. Forum of Arts. 2011 (03).

[9] Sui Wei. Cultural Context of Museum (Gallery) [J]. Contemporary Art and Investment. 2011 (6)
[10] Wang Huangsheng. Gallery - the Museum Economic in Globalization Context [M]. Shanghai: Shanghai Bookstore Publishing House. 2008.

[11] Huang Guangnan. Gallery Administration [M]. Taipei: Publisher. 1991.

[12] Tu Wei. Exploration and Analysis on Art and Design Talents Training Mode of China [J]. Asian Education Research (Japanese). 2009 (01).

[13] Yetao Huang,Zhiguo Jiang.Yue Liu and Yongtian Wang Augmented.Reality in Exhibition and Entertainment for the Public Handbook of Augmented Reality[A].Handbook of Augmented Reality.2011. 